\title{
EDITORIAL
}

\section{Do scientists need to know how science works?}

"Just as people can use their eyes to acquire knowledge without understanding how vision works, so scientists can generate knowledge about the world without understanding how science works." This provocative statement was made by Professor Peter Lipton (2005), the late Cambridge philosopher of science, in his 2004 Medawar Lecture. In the lecture he asks the question as to whether scientists would profit through a working knowledge of the philosophy of science, which is the discipline that deals inter alia with how science works. His general answer to his question is captured by the analogy in the quotation.

The twentieth century has seen two very influential philosophers of science in the persons of Karl Popper and Thomas Kuhn, and these two philosophers would be a natural starting point for the amateur philosopher of science. In fact, Lipton himself dedicates much time to them in his paper.

Popper's great contribution was his rejection of induction as a scientific method. Induction is the technical term given for generating scientific laws by observing regularities in nature. For Popper, induction was flawed because, in the words of Brian Magee (1973) "just because past futures resembled past pasts, we cannot say that future futures will resemble future pasts". Instead, Popper (1989) advocated that scientists generate theory by proposing bold conjectures to problems. Observations came after this, not to generate theory, but to test it. The quintessential embodiment of this method to Popper was Einstein, who was a contemporary of his. Thus when Einstein replaced the Newtonian framework with his own, it was not through making observations, but by postulating the general theory of relativity. He also deduced various observations from his theory that could be made under a set of conditions, in order to critically test his theory. When Arthur Eddington observed during a solar eclipse the bending of light from a star by the angle predicted by Einstein, his observation provided a confirming instance of the great man's theory. The recent search for the Higgs boson in the Large Hadron Collider is another good example of experimentation being used to test a deduction from the standard model of particle physics; a deduction made by Peter Higgs and others almost 50 years ago.

Popper's rejection of induction has drawn criticism, as has various other aspects of his philosophy. There is probably no scientist who does not engage in induction, and it is indispensible in some sciences. However, Popper's emphasis on bold conjectures during theory formation should alert scientists to the attitudes that they should cultivate. During their experiments and observations, it may be that scientists are almost boringly meticulous; but they also need to cultivate their imaginations if they are to create new and better theories.

Perhaps one of the most imaginative theorists of antiquity was Anaximander, who proposed the free suspension of the earth in space. As alluded to by Aristotle (De Caelo, B13, 295b10ff; D-K 12A26), "There are some who say that the earth remains in place because it is in equilibrium, like Anaximander among the ancients. For a thing established in the center, and equally related to the extremes, has no reason to move up or down or to the sides; and since it is impossible for it to move simultaneously in opposite directions, it will necessarily remain where it is". How did Anaximander imagine this in the $6^{\text {th }}$ century BC? It was certainly not by observation, which is probably what his teacher Thales did, when he said that the earth was supported on water (which leads of course to the problem of infinite regress - i.e. what is the water supported on, etc?). Thales may well have said this based on his observation of the ocean that surrounded Greece; he was also able to use his theory to 'explain' earthquakes - as being caused by the earth moving on the water. However, as Polanyi (1958) has said, observation has been the greatest source of error in the history of science - consider the period of time in which the human race believed that the sun moved around the earth. Polanyi too argued for the preeminence of theory over observation. 
That of course is not the end of the story, because the theories or groups of theories we generate, when accepted by a large majority, become paradigms that dictate what is acceptable or not in science. It was Thomas Kuhn (1970) who popularized the notion of a paradigm. While paradigms enable scientists to work within accepted assumptions and methods, and hence lead to great progress in science (since everyone is 'on the same page'), they can also become obstacles in the path of groundbreaking ideas. Such ideas often come from outsiders to the field. For example, John Dalton (referred to by Kuhn), who is known as a chemist because he proposed the law of multiple proportions in which atoms combine to form molecules, had previously published books on meteorology and English grammar! Einstein himself was a mere clerk in a Swiss patent office when he published his four seminal papers in 1905, and the papers probably became seminal only because Max Planck, an established academic, took notice of them. This raises the issue about how we treat outsiders, not merely to science, but even to our detailed specializations. We should rightly be wary of every claim to having broken a paradigm. However, if we are too rigid in denying publishing space to 'outsiders', we may be blocking the path to collective knowledge.

This editorial has not set out to be balanced or exhaustive in its treatment of the issues in philosophy of science. Some areas not covered are those of ethics (e.g. Blockley \& Dias, 2010) and non Western approaches to epistemology (e.g. Karunananda,1993; Arsecularatne, 2008; Goonetilake, 2008). Rather, it has tried to give some examples regarding how the way science works actually influences the progress of science. It will hopefully encourage at least a few scientists to pursue an interest in the philosophy of science. There are two take home lessons in the article, both probably against the grain of current thought and practice. One is the need to find ways of improving the imagination of scientists. Note that Kuhn (1970) described scientific education as "a narrow and rigid education, probably more so than any other except perhaps in orthodox theology"; if this is still true today, we may need to rethink science education. The second is to wisely cultivate the contributions of 'outsiders' to our disciplines, rather than fiercely defending the boundaries of our narrow specializations.

\section{REFERENCES}

1. Arseculeratne S.N. (2008). What constitutes the enterprise of modern science? Journal of the National Science Foundation of Sri Lanka 36 (4): 257 - 266.

2. Blockley D. \& Dias P. (2010). Managing conflict through ethics. Civil Engineering and Environmental Systems 27 (3): $255-262$.

3. Goonetilake S. (2008). Really different? The future of future studies. Foresight 10 (4): $43-57$.

4. Karunananda A.S. (1993). Computer modelling of thought processes. International Journal of Computer Applications in Technology 6 (2): $35-40$.

5. Kuhn T.S. (1970). The Structure of Scientific Revolutions, $2^{\text {nd }}$ edition. University of Chicago Press, Chicago, USA.

6. Lipton P. (2005). The Medawar Lecture 2004: The truth about science. Philosophical Transactions of the Royal Society of London B 360: 1259 - 1269.

7. Magee B. (1973). Popper. Fontana, London, UK.

8. Polanyi M. (1958). Personal Knowledge: Towards a Postcritical Philosophy. University of Chicago Press, Chicago, USA.

9. Popper K.R. (1989). Conjectures and Refutations: The Growth of Scientific Knowledge, $5^{\text {th }}$ edition. Routledge, London, UK.

Priyan Dias 